\title{
Phytopathology
}

\section{Salmonella Interactions with Plants and Their Associated Microbiota}

\author{
Maria T. Brandl, Clayton E. Cox, and Max Teplitski
}

First author: Produce Safety and Microbiology Research Unit, Agriculture Research Service, U.S. Department of Agriculture, Albany, CA 94563; and second and third authors: Soil and Water Science Department, Genetics Institute, University of Florida-IFAS, Gainesville, FL. Accepted for publication 8 January 2013.

\begin{abstract}
Brandl, M. T., Cox, C. E., and Teplitski, M. 2013. Salmonella interactions with plants and their associated microbiota. Phytopathology 103:316-325.
\end{abstract}

The increase in the incidence of gastroenteritis outbreaks linked to the consumption of foods of plant origin has ignited public concern and scientific interest in understanding interactions of human enteric pathogens with plants. Enteric disease caused by nontyphoidal Salmonella is a major public health burden, with the number of cases of illness linked to fresh produce, spices, and nuts surpassing those linked to foods of animal origin. Mounting evidence supports the hypothesis that colonization of plants is an important part of the life cycle of this human pathogen. Although plant responses to human pathogens are distinct from the more specific responses to phytopathogens, plants appear to recognize Salmonella, likely by detecting conserved microbial patterns, which subsequently activates basal defenses. Numerous Salmonella genes have been identified as playing a role in its colonization of plant surfaces and tissues, and in its various interactions with other members of the phyto-microbial community. Importantly, Salmonella utilizes diverse and overlapping strategies to interact with plants and their microflora, and to successfully colonize its vertebrate hosts. This review provides insight into the complex behavior of Salmonella on plants and the apparent remarkable adaptation of this human pathogen to a potentially secondary host.

Additional keywords: foodborne pathogen, fruit, vegetable, phyllosphere, rhizosphere, enteric illness, microbe-microbe interactions.

Salmonellosis caused by nontyphoidal salmonellae is the largest cause of foodborne gastroenteritis. Nontyphoidal strains of Salmonella are estimated to infect over 1 million people per year in the United States alone (http://www.epi.ufl.edu/?q=ranking therisks) (10). The public health burden is significant, accounting for several billion dollars in medical costs and $\approx 400$ deaths per

Corresponding author: M. Teplitski; E-mail address: maxtep@ufl.edu

http://dx.doi.org/10.1094/PHYTO-11-12-0295-RVW

(c) 2013 The American Phytopathological Society year (10,57). Salmonella is a major causal agent of foodborne outbreaks for which etiological agents have been determined and is ranked as the most burdensome foodborne pathogen in the United States (10). The link between salmonellosis and foods of animal origin is well known and has received considerable regulatory attention. Although the number of illness cases related to the consumption of meats has declined in recent years, the overall salmonellosis outbreak rate has remained steady due to increased risk from nontraditional sources of the pathogen. These include fresh fruit and vegetables, spices, and nuts, and underscores the importance of plants as potential sources of the pathogen $(10,26$, 57,58). From 1998 to 2007 produce was linked to more outbreaks than beef, pork, or poultry with fresh produce potentially being the riskiest food $(10,26,58)$. In addition to the significant public health burden, outbreaks of gastroenteritis linked to the consumption of produce significantly reduce demand and impact the produce industry economically (77).

Despite the magnitude of the problem, relatively little is known about traits and mechanisms that allow Salmonella to persist outside of vertebrate animals. This paucity of information is stark: over 72,000 studies in PubMed are indexed under Salmonella, with less than 100 of them regarding Salmonella-plant interactions. The majority of these publications result from studies over the last two decades, highlighting a growing interest in understanding behavior of Salmonella outside of its animal hosts.

Salmonella persistence on plants. Plants may be valuable alternate hosts for enteric pathogens by providing a refuge after excretion from the animal intestinal tract. The ability to colonize edible plants may be an effective survival strategy for Salmonella as it provides a direct route from its excretion in the environment back to its numerous herbivorous and omnivorous hosts (Fig. 1) (57). Field studies revealed that Salmonella enterica sv. Typhimurium was capable of persisting in manure-amended soils for up to 231 days, and that the pathogen was detected on aboveground parts of lettuce and parsley, and on carrots and radishes grown in these amended soils for 2 to 3 months $(40,41)$. In addition to its transfer from manure to plants, Salmonella deposited onto lettuce and parsley seedlings via irrigation water survived on plants until harvest $(40,41)$, thus corroborating the results of earlier field studies in which Salmonella Typhi was shown to survive on lettuce from the seedling stage to maturity after contamination with overhead water (29).

A three-step food-chain experiment by Semenov et al. (74) further supports the hypothesis that plants can serve as alternative 
hosts for human enteric pathogens. The authors demonstrated that Salmonella and Escherichia coli O157:H7 colonized seedlings sown into soil amended with pathogen-containing manure; cows, mice, and snails who ate these seedlings shed the pathogens in their excrements; and the shed pathogens persisted in manure or soil for at least 2 weeks (74). Consistent with the studies of Semenov et al. (74), Schikora et al. (73) demonstrated that Salmonella Typhimurium inoculated into and recovered from Arabidopsis leaf homogenates was as virulent as the inoculum grown in a nutrient-rich culture medium. Salmonella cells from leaf homogenates invaded the spleen and caused mortality in mice (73). Collectively, the above observations and the increase in salmonellosis outbreaks linked to the consumption of produce provide evidence that plant colonization by Salmonella can be part of its life cycle.

Early studies on the fitness of Salmonella in the phyllosphere revealed that this pathogen has the ability to multiply and form microcolonies on leaves, although its population sizes are often exceeded by those of plant-associated bacterial species (18). Comparative studies on lettuce leaves of different ages showed that Salmonella and E. coli O157:H7 achieved 10-fold greater population sizes on young leaves ('heart') than on the older middle leaves. Given that middle leaf exudates contained less total $\mathrm{N}$, but not less total $\mathrm{C}$, than those of young leaves and that lower growth of the pathogens on middle leaves could be complemented by addition of $\mathrm{N}$, but not of $\mathrm{C}$, to the inoculum suspension, colonization of middle leaves may have been limited by low $\mathrm{N}$ availability (16). Thus, it is likely that the lower fitness of human pathogens compared with that of plant-associated bacteria is partly rooted in the low abundance and restricted range of nutrients that they can assimilate on plant surfaces. However, plant surfaces are not homogenous and contain various microsites that represent oases of available nutrients (54) and which may support multiplication of human pathogens after contamination events. Because these sites are also attractive to plant-associated microbes, cells of enteric pathogens likely must interact and compete with indigenous microbial communities in order to occupy such preferred sites (14).
Laboratory studies demonstrated that Salmonella is capable of colonizing plants through multiple routes including wetting of leaves, contaminated soil, roots, seeds or flowers $(18,24,36)$. For colonizing bacteria, aerial plant surfaces are a challenging environment, presenting stresses such as desiccation, UV irradiation, and starvation, with only patchy nutrient availability $(38,55)$. Human pathogens on leaves have been shown to preferentially move towards stomata and colonize the vein areas, the bases of trichomes and lesions or other surface irregularities $(2,7,15,16$, 18,48-50), which may provide shelter from these stresses and increased nutrient and water availability. Hence, these microsites may offer physico-chemical conditions that are conducive not only to survival but also may be exploited by Salmonella for growth and where the human pathogen may behave partly like many epiphytic bacteria, including plant pathogens.

Salmonella genes involved in plant colonization. If the hypothesis that plants can serve as alternate hosts for enteric pathogens is correct, Salmonella should not behave solely as a transient immigrant with a restricted residence time in the plant habitat, but should harbor traits allowing for its interaction with plants and their colonization. This may include also the ability to effectively use available nutrients, evade recognition by the plant defense system and/or resist or suppress plant defense responses. Thus, it should be possible to find genotypic and phenotypic evidence of Salmonella adaptation to its life in and on plants.

Screens of Salmonella mutant libraries for those unable to attach to alfalfa sprouts or colonize tomato fruits identified 20 and 55 unique non-overlapping genes, respectively $(4,61)$ (Box 1). Even though screens in these studies were not saturating, the predicted functions of the Salmonella genes involved in plant colonization are distinct from those typically used by this pathogen for the infection of animal models, and were also distinct from those used by phytopathogens in plants (77). It is of note that the Salmonella virulence genes located on pathogenicity islands (SPIs) appear to have different roles during interactions with different plant species: in tomatoes, SPI mutants were as fit as the wild type (61), whereas in alfalfa and lettuce, SPI mutants have phenotypes that are distinct from those of the wild-type

\section{GLOSSARY}

Apoplast: the space outside of the plant cell membrane and between cells where water diffuses freely.

Biotrophic: a plant pathogen that obtains nutrients from living cells.

Curli: bacterial thin aggregative fimbriae formed by amyloid fibrils; produced by various members of the Enterobacteriaceae.

Enteric illness: human illness caused by ingestion of food that is contaminated with a pathogenic microbe or a toxic chemical.

HEp-2 cells: eukaryotic cell line derived from a carcinoma; used in studies that investigate pathogen invasion of host cells.

Infectious dose: minimum number of pathogen cells required to cause disease in a host.

Lumen: inner open space of an organ, e.g., of the intestine.

Macrophage: white blood cell that phagocytoze; act in both innate and adaptive immunity in vertebrates.

MAMP: microbe-associated molecular pattern, a conserved microbial surface component recognized by the plant innate immunity.

Nontyphoidal salmonellae: cause of most salmonellosis cases; include most pathogenic Salmonella enterica serovars, except Typhi and Paratyphi, which cause typhoid fever in humans and other primates.

Salmonella fimbriae: typically proteinaceous appendages with multiple functions, most notably in attachment. In addition to aggregative fimbriae (structures homologous to E. coli curli) encoded by the agf genes, Salmonella encode Lpf, Sef, Pef, and Fim fimbriae. The latter are not found in closely related lineages of enterics.

Soft rot: macerated plant tissue due to the degradation of the plant cell wall via pectinolytic activity of various bacterial plant pathogens.

SPI: Salmonella pathogenicity island, a chromosomal cluster of genes involved in Salmonella virulence. Subspecies of Salmonella enterica differ in the number of SPIs, some containing up to five SPIs.

SPI-1: Salmonella pathogenicity island 1, harbors genes encoding a type 3 secretion system required for invasion of epithelial and macrophage cells. The acquisition of SPI-1 separated Salmonella from the common ancestor with E. coli. All subspecies of Salmonella carry SPI-1.

SPI-2: Salmonella pathogenicity island 2, involved in replication in host cells, codes for a type 3 secretion system.

SPI-3: Salmonella pathogenicity island 3, encodes genes with various functions, including $m g t C B$ which are required for survival in host cells and virulence. 
strain $(27,39,73)$. These differences in the roles for the SPI genes could be due to the differences in the interactions of Salmonella with plant vegetative and reproductive organs, which were sampled in these studies.

rdar phenotype in Salmonella colonization of plants. The involvement of the rdar-like phenotype (Box 2) in the persistence in and on plants seems to be conserved in human enteric pathogens. Aggregative fimbriae, encoded by the agf operon, contribute to biofilm formation on HEp-2 cells and in the chicken intestine (53). Salmonella agfB and rpoS mutants (defective in the production and regulation of aggregative fimbriae, respectively) were deficient in initial attachment to the root surface of sprouts (4). agf genes also played a significant role in the colonization of the parsley phyllosphere following irrigation with Salmonellacontaminated water (52). Laboratory studies with isogenic nonrdar Salmonella mutants suggest that their fitness within tomato fruits is significantly increased compared with rdar strains (93). $E$. coli $\mathrm{O} 157: \mathrm{H} 7$ variants lacking curli fimbriae are readily recovered from $E$. coli $\mathrm{O} 157: \mathrm{H} 7$ populations associated with produce outbreaks (21). Carter et al. (21) reported that E. coli O157:H7 curlipositive variants (equivalent to Salmonella rdar) have greater survival under low nutrient stress conditions than their curli-negative variants (equivalent to non-rdar Salmonella), whereas the opposite trend is observed for acid stress (21). Increased acid stressresistance in curli-negative variants of E. coli $\mathrm{O} 157: \mathrm{H} 7$ is due to the presence of a functional RcsB, which positively regulates acid resistance in $E$. coli but negatively regulates curli production (21). Thus, while the molecular and physiological basis of the increased competitive fitness of Salmonella non-rdar mutants over their rdar strain in tomato fruit is not clear, it is possible that like in $E$. coli $\mathrm{O} 157: \mathrm{H7}$, the selection for the non-rdar mutant cells over the wild-type cells results from enhanced tolerance of the non-rdar strain to acid stress in tomato fruit tissue and from a lack of nutrient limitation, which otherwise would favor the rdar genotype.

Cellulose production contributes to the rdar phenotype along with aggregative fimbria (Box 2) and is produced at different levels among Salmonella strains recovered from outbreaks related to fruits and vegetables $(68,93)$. This surface polymer, which was first identified as an important host plant attachment factor in
Agrobacterium tumefaciens (60), and later as a fitness determinant in Pseudomonas fluorescens in the sugar beet rhizosphere and phyllosphere (32), also plays a role in the binding of Salmonella and E. coli to alfalfa sprouts $(6,59)$. In this Focus Issue, Kroupitski et al. (47) report that Salmonella mutants in bcsA, misL, and yidR, encoding a cellulose synthase catalytic subunit, an adhesin of the autotransporter family expressed from SPI-3, and a putative ATP/GTP-binding protein, were impaired in attachment to and persistence on lettuce leaves stored at cold tempera-

\section{BOX 1}

In planta monitoring of Salmonella gene regulation: technological considerations. To better understand how Salmonella interacts with plants and to test whether its persistence in plants is a co-evolved part of its lifecycle, it will be important to define the factors that allow Salmonella to colonize its various animal and plant hosts. There is a need for sensitive tools to define Salmonella gene regulation in planta and its responses to specific plant metabolites. While mutant screens are ideally suited for the identification of genes required for a specific step in the interactions of enterics with plants, e.g., attachment to surfaces (6), they will likely miss more complex phenotypes, in which multiple inputs are involved in modulating a behavior. Various promoter-probe screens are better suited for the identification of the genes that are differentially regulated during attachment or persistence within plants, and thus contribute to the complex phenotype without necessarily being required for persistence in or on plants. For example, a differential fluorescence induction (DFI) screen combined with fluorescenceactivated cell sorting (FACS) technology led to the identification of $\approx 50$ unique genomic fragments that induced the differential fluorescence of the reporter (61). These differentially regulated promoters functions include Salmonella metabolism within plants and its ability to recognize specific plant metabolites. Single mutants in the genes corresponding to the promoters identified with DFI-FACS had no fitness defect in plants, consistent with the properties of DFI screens (61).

\section{FIGURE 1}

Lifecycle of enteric bacteria. Excretion from a host and subsequent colonization of plants may be part of the lifecycle of enteric bacteria. Plants germinating from cow manure are not uncommon, as in this photograph of an alfalfa seedling growing on manure in a grazed pasture in Archer, FL. Inset:

samples from the cow manure, rhizosphere, and surfacesterilized shoot and root tissues of the alfalfa seedling in the photograph were homogenized in phosphate-buffered saline and plated on xylose lysine deoxycholate agar (XLD) medium (Oxoid, Hampshire, UK) and incubated at $42^{\circ} \mathrm{C}$ to detect fecal coliforms (yellow colonies on XLD agar). Relatively few coliforms were detected in the aged bulk manure and in the rhizosphere; however, substantial populations of presumed fecal coliforms were detected inside the plant tissue.

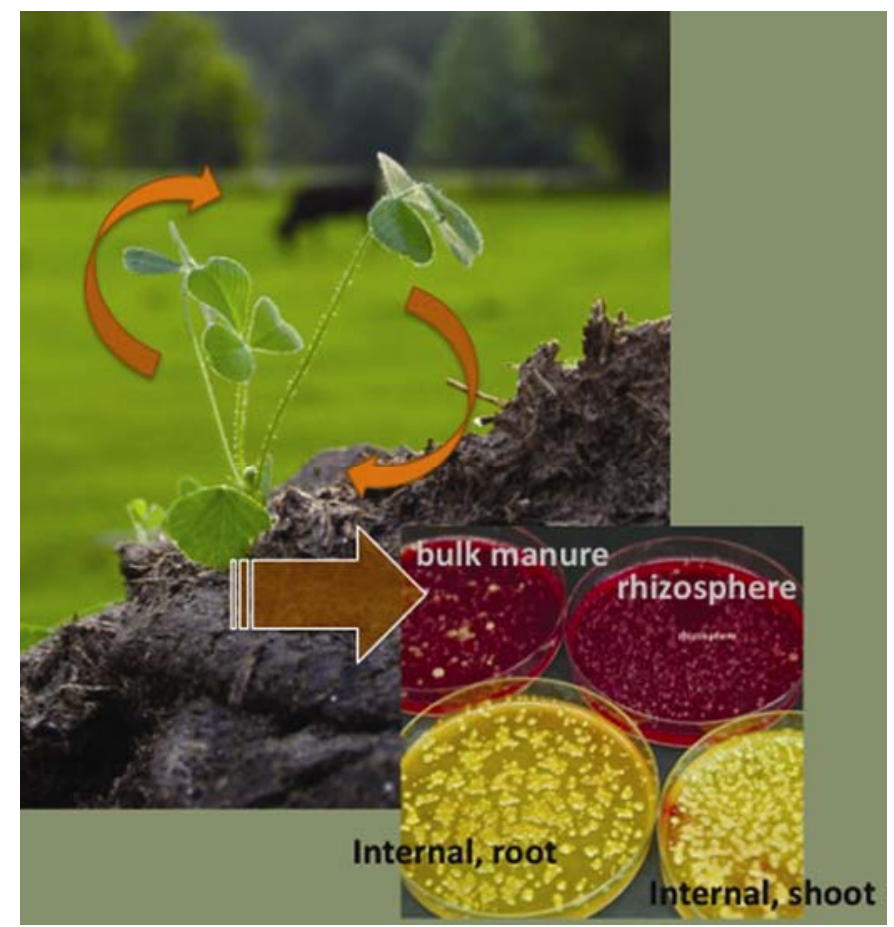


tures (47). It is noteworthy that MisL also affects binding of Salmonella to fibronectin in animal hosts (28). Hence, Salmonella appears to use some of its virulence factors targeted at mammalian hosts to interact with plants, and also relies on factors that are commonly used in phytobacteria for attachment to plants.

Motility genes. Motility factors, such as flagella, play a role in the survival of Salmonella on plants. Genes involved in flagella synthesis (but not those involved in chemotaxis) were required for attachment of Salmonella serovar Typhimurium to lettuce leaves and serovar Senftenberg to basil leaves, and mutations affecting Salmonella motility and chemotaxis significantly inhibited its penetration into stomata $(12,48)$. This is consistent with the observation that E. coli $\mathrm{O} 157: \mathrm{H} 7$ genes involved in motility and chemotaxis were strongly upregulated within the first $15 \mathrm{~min}$ of exposure to lettuce leaf lysates (51). Salmonella also chemotaxes toward lettuce root exudates (44) and movement of the pathogen up the xylem in Arabidopsis thaliana roots was eliminated and invasion decreased in flagella- and motility-minus mutants (24). However, within red ripe tomatoes (infected with Salmonella through shallow wounds), mutations in neither the Salmonella flhDC (master regulator of the flagellar regulon) nor fliF (resulting in a non-flagellated mutant with a functional motor) had an effect on competitive fitness (61). Additionally, $f l j B$ and the fli and flg operons, which code for flagellar synthesis in Salmonella, were downregulated during its colonization of soft rot lesions caused by Dickeya dadantii on cilantro and lettuce (34). Therefore, motility and chemotaxis are likely to be required during the early stages of the interactions of these enteric pathogens with plants, but not once they gain entry into plant tissues where nutrients may be plentiful. Flagella may also function as microbial-

\section{BOX 2}

rdar phenotype. Under laboratory conditions on agar surfaces, most wild-type strains of Salmonella form rough and dry colonies, which can absorb Congo Red dye. This phenotype is known as "rdar". It requires multiple regulatory inputs, which converge to control the production of cellulose and aggregative fimbriae (curli) (67). Mutations in any of the corresponding genes result in a variety of non-rdar phenotypes (e.g., bdar, saw, and pdar). Interestingly, non-rdar mutants are more common in collections of Salmonella isolates recovered from produce-related outbreaks than in those of clinical strains or those recovered from meats $(76,93)$ (Fig. 2). associated molecular patterns (MAMPs) in induction of plant defenses since nonflagellated mutants of Salmonella had an increased endophytic fitness in alfalfa roots (39).

Salmonella genes STM0278 and STM0650, which are involved in multicellular surface spreading ("swarming"), were required for colonization of seedling surfaces (4). While it is not known how these genes affect swarming, it is tempting to speculate that swarming has other roles in addition to locomotion toward the preferred colonization sites in the rhizosphere $(27,39)$. Differentiation of Salmonella into multicellular surface swarms is associated with global physiological changes (88), including increased resistance to antibiotics mediated by the cys $B$ gene $(83,84)$. Interestingly, cys $B$ was differentially regulated inside tomatoes of different varieties, with the strongest expression of cysB in tomatoes of cv. Hawaii 7997, which is resistant to certain races of Ralstonia solanacearum (61). It is tempting to surmise that this enhanced resistance to the phytopathogen is at least partly mediated by plant basal defense antimicrobials that may have upregulated $c y s B$.

The role of plant genotype in interactions with Salmonella. While scientific consensus on the issue of plant-associated gene regulation in human enteric pathogens is beginning to emerge, the role of plant genotype in Salmonella-plant interactions remains significantly less understood. Several research groups demonstrated that the outcome of interactions with Salmonella depends on the plant species and genotype $(7,8,42,44,61)$. Indeed, internalization of Salmonella into plant tissue varies greatly among plant species (42) and crop colonization differs among cultivars of a given species $(7,8,44)$. There was an approximately 100 -fold difference in the phyllosphere populations of Salmonella on four tomato varieties, with Solanum pimpinellifolium variety WVa700 supporting the lowest number of bacteria (7). Of note, WVa700 was also significantly less susceptible to bacterial speck caused by Pseudomonas syringae pv. tomato (7). The plant genotype has an important role also in the proliferation of E. coli $\mathrm{O} 157: \mathrm{H} 7$ in the lettuce phyllosphere (64). These observations suggest that specific genetic factors pertaining to the plant response to microbial colonization drive the outcome of the interaction of enteric pathogens with plants, or that differences in physicochemical properties, such as availability of certain nutrients or surface morphology, associated with different crop genotypes impact proliferation of Salmonella and E. coli on and inside plants. These discoveries point to the potential of breeding for resistance to colonization by enteric pathogens, although the economic feasibility of breeding for resistance to these organisms is not yet clear (77). It remains unknown whether there is a correlation between plant basal immune responses to phytopathogens and to human

\section{FIGURE 2}

Phenotypes of Salmonella enterica isolates on a Congo Redcontaining plate. The characteristic red wrinkled appearance (rdar phenotype) is seen in colonies of the wild-type

S. Typhimurium 14028 (right, middle row, also see notations on the grayscale inset). $S$. Newport (from a tomato field on the Eastern Shore of Virginia, top left), two S. Braenderup isolates from clinical patients in a tomato outbreak (bottom left and top right corners, indicated with "B"), Salmonella Agona (left, middle row; " $\mathrm{A}$ "), Montevideo (center, "Mo") and Michigan (middle, top row," Mi") are non-rdar. Spontaneous non-rdar mutants can arise when rdar strains are passaged through tomatoes, e.g., the two non-rdar spontaneous mutants (93) of S. Typhimurium 14028 in the forefront.

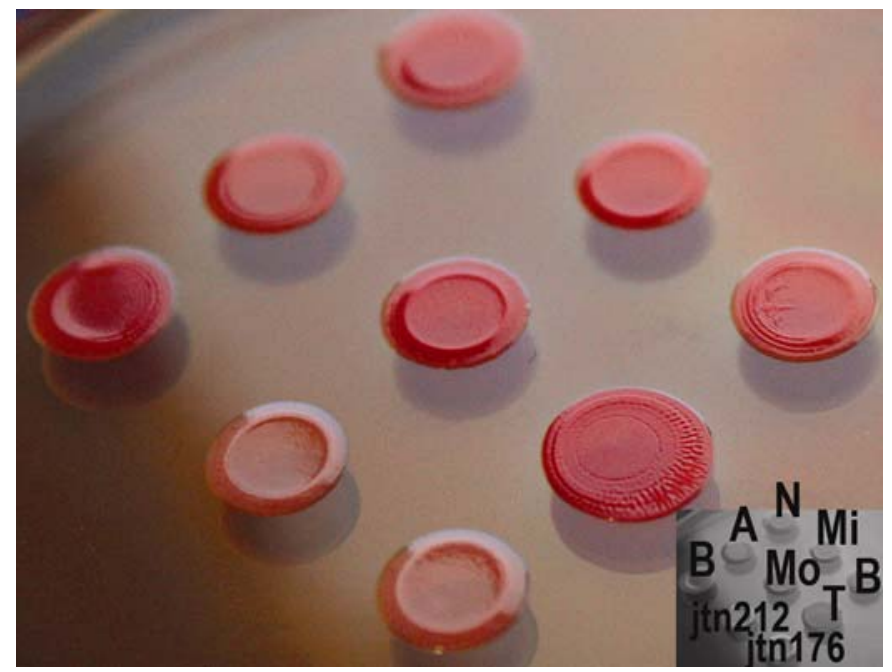


pathogens. Such a correlation would provide an opportunity to integrate breeding for increased basal resistance of crops to both plant and human enteric pathogens.

Evidence of Salmonella recognition by plants. Once Salmonella has gained entry into plant tissue, such as the leaf mesophyll, its presence in the plant apoplast may trigger sophisticated plant defenses aimed at inhibiting microbial multiplication and potential invasion by plant pathogens. There is increasing evidence that plants respond to Salmonella via basal defense pathways. In support of this hypothesis, transcriptome analysis of Arabidopsis thaliana leaves infiltrated with E. coli O157:H7 revealed that the human pathogen upregulated PAMP-inducible genes (82). Suppression of plant defense functions by phytopathogenic bacteria relies partly on type 3 secretion system (TTSS). Endophytic colonization of Medicago spp. roots by Salmonella was enhanced in mutants lacking flagella and SPI-1 TTSS indicating that when present, these bacterial surface components may be perceived by the plant, thereby inhibiting Salmonella colonization via activation of plant innate immunity (39). Shirron and Yaron (75) suggested that an increase in the oxidative burst of tobacco protoplasts during co-incubation with a Salmonella invA mutant (defective in SPI-1 TTSS) resulted from a lack of suppression of the tobacco defense response (75). In a similar fashion, Salmonella mutants in invA, prgH, ssaV, and ssaJ, all of which are defective in SPI-1 or SPI-2 TTSS structures, showed reduced colonization of Arabidopsis thaliana leaves compared with the wild type, possibly due to a lack of plant defense suppression (73). Recently, it was reported that SseF, a TTSS effector of $S$. enterica can induce the hypersensitive response after transfer into tobacco by Agrobacterium tumefaciens or Xanthomonas campestris pv. vesicatoria, which may indicate a nonhost response by the plant basal defense (85).

The O-antigen of Salmonella Enteritidis is implicated in attachment and colonization of alfalfa sprouts (6). Comparative studies in Arabidopsis thaliana showed that the O-antigen also plays a role in eliciting a plant response since Salmonella serovars expressing this antigen (e.g., Senftenberg) caused leaf chlorosis and wilting; on the contrary serovars of a different serogroup did not induce such symptoms despite considerable colonization by all of the tested serovars after their infiltration into the leaves (11). Therefore, plants may sense the presence of human pathogens with pathways additional to those involved in recognition of common plant-associated microbes.

Although Salmonella can multiply in the apoplast and was observed intracellularly in Arabidopsis thaliana protoplasts and in tobacco cultured cells $(72,75)$, its ability to infect intact cells of whole living plants has not been demonstrated. However, as implied above, there is increasing evidence that plants have the ability to recognize enteric pathogens, including their MAMPs with basal defense signaling pathways. A defense-related PR1 protein was upregulated after inoculation with Salmonella in both Arabidopsis thaliana and lettuce $(39,44)$. Salicylic acid-dependent and -independent plant defenses were triggered by flagella and components of the TTSS (39). In this Focus Issue, Roy et al. (69) report that E. coli $\mathrm{O} 157: \mathrm{H} 7$ induces greater levels of expression of the plant defense gene PR1 in Arabidopsis thaliana leaves than Salmonella (69). They additionally corroborate previous findings by Kroupitski et al. (50) that Salmonella triggers weak stomatal closure in lettuce and provide evidence of a stronger stomatal immunity against E. coli O157:H7 (50). This weaker immune response to Salmonella compared with that to E. coli $\mathrm{O} 157: \mathrm{H} 7$ may explain their finding that Salmonella has a greater ability to colonize the leaf apoplast.

Exposure of Arabidopsis thaliana to Salmonella Typhimurium 14028 and E. coli elicited measurable and temporally distinct transcriptomic responses in the plant. In total, 114 plant genes $(\approx 10 \%$ of those activated in response to Salmonella) were acti- vated in response to Salmonella at 2 and $24 \mathrm{~h}$ after inoculation (73). One hundred and sixty Arabidopsis thaliana genes were commonly up-regulated in response to Salmonella, E. coli $\mathrm{K} 12$, and $P$. syringae; however, the magnitude of specific responses to Salmonella or E. coli was significantly (50 to $100 \times$ ) less than to $P$. syringae (73). In another study, inoculation of Arabidopsis thaliana with $E$. coli $\mathrm{O} 157: \mathrm{H} 7$ elicited responses that are distinct from those elicited by the plant pathogen $P$. syringae pv. tomato DC3000, but similar to those elicited by its attenuated mutants (82). The latter included genes belonging to hormone and stress response pathways with two exceptions: genes encoding a jasmonic acid methyl transferase and a putative anthocyanidin synthase, which were up-regulated only in response to TTSS mutants of DC3000 (82). These observations suggest that plants recognize and respond to enteric pathogens as "general" endophytes, and the defenses mounted by plants in response to phytopathogens or symbionts are distinct from those elicited by these human enteric pathogens.

Proliferation of Salmonella and E. coli O157:H7 in some plant tissues has been reported to cause disease-like symptoms. For example, root inoculation of lettuce with $10^{5}$ cells of Salmonella Dublin stunted growth of the seedlings and led to a modest reduction in plant biomass upon extended cultivation ( $>12$ days) (44). In Arabidopsis, immersion of seedlings into a dense suspension of Salmonella or infiltration of leaves with the pathogen can elicit chlorosis, wilting, or tissue necrosis $(11,72)$. Infiltration of the wild-type Salmonella into Arabidopsis leaves elicited chlorosis to the same extent as the infiltration of $\mathrm{MgCl}_{2}$ solution; however, lesions elicited by Salmonella SPI-1 and SPI-2 mutants were approximately twice as large as the controls (73). The appearance of plant disease symptoms in Arabidopsis was associated with the ability of Salmonella to overcome jasmonate-mediated plant defenses (72), whereas studies by Iniguez et al. (39) implicated Salicylic acid-induced defense pathways in the response of Arabidopsis to Salmonella (39). These findings suggest that the human pathogen is recognized by plants and that general host defenses are induced, although the physiological consequences of these defenses are not consistent from one study to another and need to be better understood.

Interactions of Salmonella with phytobacteria. In animal studies, the ability of Salmonella to colonize the intestine is greatly dependent on its success in becoming established among the host gut microflora, either by manipulating the host's physiology or by utilizing nutrients that are not used efficiently by the native microbes $(80,91)$. Several recent studies have also explored potential mechanisms used by Salmonella to interact with members of the native plant-associated microflora.

The importance of phytobacteria in the persistence of human enteric pathogens on plants first came to light from supermarket produce surveys that demonstrated that $60 \%$ of produce showing symptoms of soft rot also harbored presumptive Salmonella (89). Later laboratory studies revealed that plant tissue macerated by pectinolytic pathogens such as D. dadantii (Erwinia chrysanthemi) and Pectobacterium carotovorum, promoted growth of Salmonella Typhimurium and E. coli $\mathrm{O} 157: \mathrm{H} 7$ to population densities approximately 10 times greater than on healthy plants; the sudden increase in proliferation of the human pathogens coincided with the appearance of soft rot symptoms $(15,34,62,92)$ (Fig. 3). Transcriptomic studies by Goudeau et al. (34) revealed that Salmonella cells colonizing lettuce and cilantro leaf soft rot lesions caused by $D$. dadantii utilize a broad range of nutrients made available through the pectinolytic activity of the plant pathogen (34). These include fucose and rhamnose, two substrates for the production of propanediol, which along with ethanolamine, can serve as carbon sources under anaerobic conditions (34). Propanediol utilization is required for Salmonella replication in macrophages and colonization of the chicken lumen $(37,45)$. 
Ethanolamine utilization confers a competitive advantage onto Salmonella in the lumen of the inflamed intestine in the mouse colitis model (81). Commonalities between soft rot lesions and the host intestine such as anaerobic conditions and nutritional resources indicate an important overlap in ecological niche and may explain the adaptation of Salmonella to macerated leaf tissue (34).

Biotrophic plant pathogens, like $P$. syringae and Xanthomonas campestris, were also shown to promote growth or survival of Salmonella and enterohaemorrhagic $E$. coli on plants $(2,3,9)$. Formation of lesions on leaves by both these phytopathogens was associated with an increase in availability of total sugars, specifically, innositol and sucrose (3). While it is tempting to speculate that the increased leakage of these compounds favors proliferation of the human pathogens at the lesion sites, other substrates and factors may also be involved since E. coli $\mathrm{O} 157: \mathrm{H} 7$ is unable to utilize innositol, and most Salmonella serovars are unable to utilize sucrose. Furthermore, the increase in the availability of these carbon sources in plant lesions caused by $X$. campestris did not account fully for the increased proliferation of Salmonella and EHEC in the lesions caused by either $X$. campestris or $P$. syringae (3). An increase in growth similar to that observed in response to the biotrophic phytopathogens was observed on lettuce leaves that were mechanically damaged or showed symptoms of tip burn (dry lesions on leaf margins resulting from a physiological disorder) $(2,15)$.

Phyllosphere bacterial communities are diverse, both functionally and structurally. In addition to erwinias, xanthomonads, and pseudomonads, which are ubiquitous on leaf surfaces, Salmonella may reside with closely related coliforms that are frequently present on plants, and with $\beta$ - and $\alpha$-proteobacteria, firmicutes, bacteroidetes, and actinobacteria $(56,65)$. Metagenomic studies revealed that the decreased abundance in ready-to-use carbon and ammonium in a biofilm composed of spinach epiphytes likely resulted in increased competition of the enteric pathogen $E$. coli O157:H7 with other spinach leaf microbes capable of converting unavailable $\mathrm{C}$ and $\mathrm{N}$ to their bio-available forms (22). Competition for nutrients with members of the Enterobacteriaceae appeared to significantly reduce the fitness of Salmonella and E. coli $\mathrm{O} 157: \mathrm{H} 7$ in plant-associated ecological niches $(23,24,56)$. In contrast, the presence of a member of the Burkholderiales that utilizes different carbon sources than Salmonella does modestly increase proliferation of E. coli $\mathrm{O} 157: \mathrm{H} 7$ in the lettuce phyllosphere (23). A similar trend was observed with other phytobacteria that stimulated growth of E. coli $\mathrm{O} 157: \mathrm{H} 7$ in vitro and in planta (56). In leaf tissue macerated by $D$. dadantii, a phytopathogen belonging to the Enterobacteriaceae, Salmonella underwent high growth rates and its populations sizes were highly correlated with those of the soft rot pathogen throughout disease development (34). Goudeau et al. (34) suggested that this apparent lack of competition with the plant pathogen stems from the extensive activity of the Salmonella propanediol catabolitic pathway, along with the synthesis of its co-factor, cobalamin, which are both absent in $D$. dadantii (34). Thus, although $D$. dadantii makes the necessary substrates for propanediol synthesis and catabolism available to Salmonella through pectinolysis, the plant pathogen itself utilizes the oligogalacturonides released from the plant cell wall, thereby creating a nutritional environment with resources partitioned for both bacterial species.

Competition for nutrients is unlikely to be the sole mechanism by which enteric pathogens can be excluded from, or become minor members of, plant-associated bacterial communities (56). On plant surfaces, they may be exposed to phages and antibioticproducing phytobacteria. For example, a strain of $P$. syringae (with previously demonstrated fungicidal activities) reduced growth of E. coli O157:H7 on wounded apples by 10- to 1,000fold (43). These discoveries led to experiments on biological control of human enteric pathogens in produce, such as those by Fett (30) who showed that a well-characterized biocontrol strain of Pseudomonas fluorescens 2-79 effectively reduced Salmonella populations on alfalfa sprouts (30). Likewise, bacteriophages can considerably reduce the contamination of various produce with enteric pathogens (78). This suggests that phages and known biocontrol bacteria may be useful as potential tools for controlling enteric pathogens throughout the produce production cycle. It is important, however, to consider that zero tolerance for most human pathogens on fresh fruit and vegetables implies that even the most effective biocontrol agent would need to be integrated as one of several hurdle technologies in a general control strategy.

Besides mechanisms of metabolic cooperation or competition between phytobacteria and Salmonella, cell-to-cell signaling in multi-species microbial consortia on plants may also occur. The contribution of signaling via quorum sensing circuits mediated by either $\mathrm{N}$-acyl homoserine lactones (AHL) or the autoinducer-2 (AI-2) signal to the behavior of Salmonella in plant-associated bacterial communities has been tested. Even though the Salmonella AHL receptor encoded by sdiA was involved in the responses of this bacterium to AHLs from phytobacteria (Box 3), in vivo expression technology and fitness studies conclusively demonstrated the lack of the role for SdiA and its regulon in interactions with pectobacteria in soft rots on several crop species (62). Despite the fact that the Salmonella luxS gene was expressed during its invasion of a soft rot, AI-2-based signaling in Salmonella did not appear to have an important role during its interactions with the plant pathogen $P$. carotovorum on tomato fruit, as demonstrated by Cox et al. (25) in this Focus Issue.

Salmonella has the ability to form single- and mixed-species aggregates in the phyllosphere $(18,19)$. As reported by Poza-

\section{FIGURE 3}

Soft-rot bacteria promote proliferation of Salmonella in plants. An increased proliferation of Salmonella and Escherichia coli in plants infected with soft-rot bacteria has been observed in the

market place (89) and under laboratory conditions $(15,19,34,62)$.

In this experiment (J.T. Noel, unpublished data), Salmonella Typhimurium 14028 ( $\approx 100$ to 500 cells) was co-inoculated with $\approx 3$ million cells of hypervirulent Pectobacterium carotovorum SR38 by injection into the tomato pericarp and incubated at $22^{\circ} \mathrm{C}$. For enumeration, tomatoes were macerated in phosphatebuffered saline and dilution-plated onto xylose lysine deoxycholate agar. The brown and green lines represent the growth of Salmonella with and without Pectobacterium soft rot, respectively. Inset: appearance of representative tomatoes throughout the experiment.

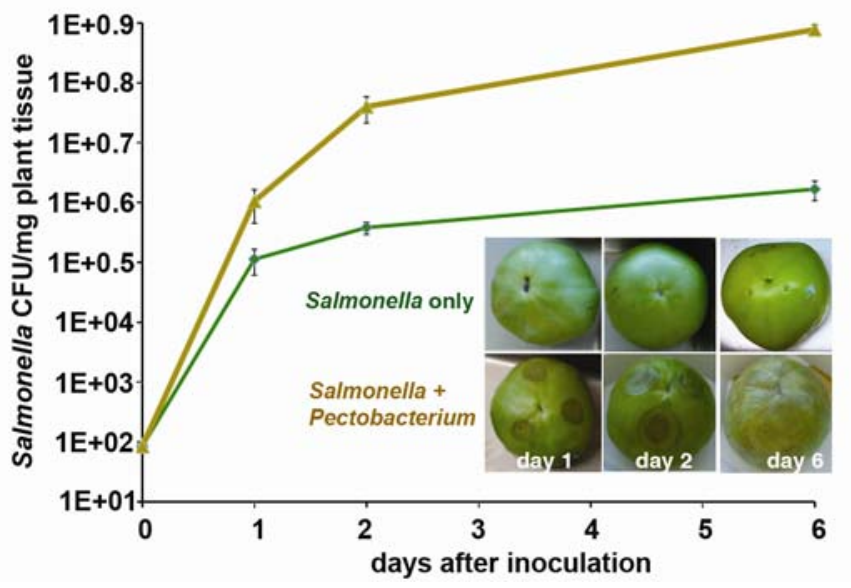

Vol. 103, No. 4, 2013 
Carrion et al. (63) in this Focus Issue, aggregates formed by common epiphytes affect the fitness of the human pathogen in the phyllosphere. Salmonella cells that landed in preexisting aggregates of $P$. syringae, $P$. fluorescens, and two Erwinia species had a greater probability of surviving dry conditions on lettuce and cilantro leaves than as solitary cells (63). These observations suggest that human pathogens may find refuge not only in particular physical microsites on plants but also in microbial conglomerates where protection from adverse conditions outweighs potential competition and antibiosis from other plant colonists. In general, Salmonella and EHEC appear to be successful secondary colonists, benefiting from the action of phytopathogens, e.g., suppression of plant defense and plant tissue damage (lesions, water soaking, and soft rots). The ability to outcompete or to avoid nutrient competition with phytopathogens, and to resist the action of antimicrobials released by phytopathogens would be important in determining the outcome of the interactions of these enteric bacteria with plant-associated microorganisms.

Interactions of Salmonella with plant-associated protists. Within human hosts, Salmonella utilizes sophisticated systems to invade nonphagocytic cells, and establish the Salmonella-containing vacuole (SCV), which it exploits for survival and replication (31). In the environment, Salmonella predation by protists results in its entrapment in a food vacuole where it experiences

\section{BOX 3}

Peculiarities of Salmonella quorum sensing (QS). Similarly to most Gram-negative bacteria, Salmonella can detect certain $\mathrm{N}$-acyl homoserine lactones (AHL) and autoinducer-2. Exceptionally, the Salmonella AHL receptor, SdiA, does not have a cognate AHL synthase, nor does Salmonella (or its close relatives E. coli, Enterobacter, Citrobacter, Chronobacter, and Klebsiella) produce AHLs (1). Phylogenetic analyses revealed that SdiA likely originated from the Pseudomonas RhIR, which was horizontally acquired as the rh/R-rhll cluster by the common progenitor of enterics, including Salmonella, Erwinia, and Pantoea. The rh/R-rhll cluster further evolved to expR-expl (phzR-phzl) within this common progenitor, while Salmonella, E. coli, Enterobacter, Citrobacter, Chronobacter, and Klebsiella lost the $\mathrm{AHL}$ synthase gene (70), but retained the $\mathrm{AHL}$ receptor, SdiA. In all these organisms, SdiA is encoded upstream of the gacA ortholog. In Salmonella, the ability of SdiA to regulate the downstream genes in the presence of AHLs is temperature-dependent. Unlike phytopathogens, where AHL-mediated QS controls a number of genes involved in virulence, SdiA upregulates less than a dozen genes whose functions are currently unknown (1).

Salmonella possesses a second potential signaling system based on the Al-2 molecule produced via the synthase LuxS. Salmonella receives the signal via the IsrACDBFG operon, an $A B C$ transporter with homology to the rbs ribose transporter of $E$. coli. The sole known function of the IsrACDBFG operon in Salmonella is the uptake and processing of Al-2. However, the primary role of luxS appears to be degradation of toxic intermediates in the activated methyl cycle (AMC), which makes distinguishing between metabolic changes related to the luxS genotype and those resulting from Al-2 signal exchange difficult. Microarray studies have shown that only a small portion of the luxS-responsive genes $(7.9 \%$ in Salmonella, $1.9 \%$ in E. coli and $9.2 \%$ in Streptococcus mutans) also respond to exogenous Al-2 and an inability of exogenous Al-2 to rescue the luxS mutation in Salmonella. This underscores the complexity and uncertainties associated with role of luxS in Al-2 signaling in Salmonella. conditions that overlap with those in the SCV (66). The human pathogen Legionella pneumophila is known to interact with Acanthamoeba and survives in its cysts, a process that increases the infectivity of Legionella (71). Salmonella also appears to resist digestion by Acanthamoeba and certain ciliates commonly present in agricultural soils and on preharvest and postharvest vegetables, which may serve as additional environmental reservoirs $(20,35,79)$. Tolerance of Salmonella to digestion in Tetrahymena vacuoles results in its excretion in the protist's fecal pellets where the human pathogen survives at greater rates than as single cells (20). The release of fecal pellets containing intact Salmonella cells was observed on plants in the laboratory (35). Passage through Tetrahymena induces a large number of regulatory changes affecting between 989 and 1,282 genes or approximately $25 \%$ of the Salmonella genome (66). Many genes that were differentially regulated are involved in anaerobiosis, virulence, stress response (oxidative, osmotic, acid, and antimicrobial stress, as well as SOS response), indicating similarities in the physiology of Salmonella cells residing in Tetrahymena vacuoles to those in macrophages and epithelial cells. The acid resistance genes, adiA and adiY, were strongly upregulated and played a role in Salmonella resistance to digestion by Tetrahymena (66). Rehfuss et al. (66) reported that the induction of acid stress response genes in Tetrahymena vacuoles imparts an enhanced resistance to subsequent acid stress upon Salmonella, and suggested that it may improve the pathogen's ability to survive the acidic stomach $\mathrm{pH}$ of its hosts. Such pre-adaptation may reduce the infectious dose of Salmonella in humans.

The passage of Salmonella through the amoeba Acanthamoeba polyphaga is associated with survival within contractile vacuoles, a process that relies on the $s s e C$, ssaU, and phoP genes $(13,79)$. These genes are part of SPI-2, which is responsible for intracellular replication in macrophages. Once established within the contractile vacuole, the bacteria entered logarithmic growth producing a population of over 200 cells that were able to persist for at least 4 days (33). The surviving Salmonella are subsequently able to multiply on the amoeba's waste products. Passage also induces a filamentation response which appears to provide protection from predation, although the mechanisms involved are unclear.

Interactions of Salmonella with plant-associated fungi. Fungi are prevalent members of plant microbial communities. Thus, it is highly likely that Salmonella encounters and interacts with fungi during its residence on plants. Various types of interactions between bacteria and fungi, ranging from antagonistic to beneficial, have been described (46). The attachment of Salmonella cells to fungal species in the cilantro phyllosphere has been observed (14). Furthermore, laboratory studies demonstrated the formation of large and dynamic Salmonella biofilms on Aspergillus niger, a common colonizer of plant surfaces, whereas E. coli, Pseudomonas agglomerans, and Pseudomonas chlororaphis were unable to attach to the fungus and produce biofilms (17). Differences in colonization of Aspergillus were mirrored by differential binding of the bacterial species to chitin, an important component of fungal cell walls. Cellulose production in Salmonella was identified as the attachment factor mediating this relationship. It remains unclear whether Salmonella benefits directly from its association with Aspergillus, or other fungi, but it seems probable that the hyphae may vector the attached bacteria to new habitats or that their exudates provide additional nutrients to the human pathogens.

Fungi may also benefit human pathogens through habitat modification. Co-inoculation of tomato, potato, and onion tissue with Salmonella and Rhizopus caused a significant increase in Salmonella population sizes compared with its inoculation alone (90). Similarly the postharvest fungal pathogens Alternaria alternata and Cladosporium spp. enhanced the growth of Salmonella in 
ripe tomato fruit, likely via alkalinization of the plant tissue resulting from their proteolytic activity $(86,87)$. Hence it appears that fungi may not only provide enhanced access to growth substrates by degrading the plant tissue but may additionally reduce environmental stresses that inhibit Salmonella.

\section{CONCLUSIONS}

Outbreaks of gastroenteritis linked to the consumption of fresh fruits and vegetables have provided the rationale for investigating the biology of Salmonella on plants. Numerous studies in this new multidisciplinary field of research have yielded important discoveries that continue to challenge the dogma that Salmonella is best defined as an enteric colonist. Key studies, including those in this Focus Issue, point to the ability of this human pathogen to interact with plants and with the plant-associated microflora. It is clear that Salmonella can sense subtle environmental cues brought about by the genotype or physiological state of its plant host and respond with distinct patterns of gene expression accordingly. Plants also recognize Salmonella and activate basal defenses in response to the human pathogen when at high densities and in close contact with plant cells in the apoplast. It is still unclear, however, whether Salmonella is a clever opportunist that shows sufficient versatility under rare conditions in the plant environment to proliferate to infectious doses, or if its behavior on plants results from an evolutionary adaptation to use plants as an important vector to infect vertebrate hosts through their dietary intake.

\section{ACKNOWLEDGMENTS}

Preparation of this manuscript was supported by the USDA-NIFA AFRI grant 2011-67017-30127 to M. Teplitski, by the United States Department of Agriculture, Agricultural Research Service CRIS project 5325-42000-046 funds to M. T. Brandl, and by a USDA-NIFA postdoctoral fellowship grant 2012-67012-19708 to C. E. Cox, M. T. Brandl, and M. Teplitski. We thank W. J. Zaragoza and M. Fatica for designing Figure 2 and J. T. Noel for sharing unpublished data presented in Figure 3 of this publication.

\section{LITERATURE CITED}

1. Ahmer, B. M. 2004. Cell-to-cell signalling in Escherichia coli and Salmonella enterica. Mol. Microbiol. 52(4):933-945. doi:10.1111/j.13652958.2004.04054.x

2. Aruscavage, D., Miller, S. A., Ivey, M. L., Lee, K., and LeJeune, J. T. 2008. Survival and dissemination of Escherichia coli $\mathrm{O} 157: \mathrm{H} 7$ on physically and biologically damaged lettuce plants. J. Food Prot. 71(12):2384-2388.

3. Aruscavage, D., Phelan, P. L., Lee, K., and LeJeune, J. T. 2010. Impact of changes in sugar exudate created by biological damage to tomato plants on the persistence of Escherichia coli O157:H7. J. Food Sci. 75(4):M187M192. doi:10.1111/j.1760-3841.2010.01593.x

4. Barak, J. D., Gorski, L., Liang, A. S., and Narm, K. E. 2009. Previously uncharacterized Salmonella enterica genes required for swarming play a role in seedling colonization. Microbiology 155(Pt 11):3701-3709. doi:10.1099/mic.0.032029-0

5. Barak, J. D., Gorski, L., Naraghi-Arani, P., and Charkowski, A. O. 2005. Salmonella enterica virulence genes are required for bacterial attachment to plant tissue. Appl. Environ. Microbiol. 71(10):5685-5691. doi:10.1128/ AEM.71.10.5685-5691.2005

6. Barak, J. D., Jahn, C. E., Gibson, D. L., and Charkowski, A. O. 2007. The role of cellulose and $\mathrm{O}$-antigen capsule in the colonization of plants by Salmonella enterica. Mol. Plant-Microbe Interact. 20:1083-1091. doi: 10.1094/MPMI-20-9-1083

7. Barak, J. D., Kramer, L. C., and Hao, L. Y. 2011. Colonization of tomato plants by Salmonella enterica is cultivar dependent, and type 1 trichomes are preferred colonization sites. Appl. Environ. Microbiol. 77(2):498-504. doi:10.1128/AEM.01661-10

8. Barak, J. D., Liang, A., and Narm, K. E. 2008. Differential attachment to and subsequent contamination of agricultural crops by Salmonella enterica. Appl. Environ. Microbiol. 74(17):5568-5570. doi:10.1128/AEM.01077-08
9. Barak, J. D., and Liang, A. S. 2008. Role of soil, crop debris, and a plant pathogen in Salmonella enterica contamination of tomato plants. PLoS One 3(2):e1657. doi:10.1371/journal.pone.0001657

10. Batz, M. B., Hoffman, S., and Morris, J. G. 2011. Ranking the Risks: The 10 Pathogen-Food Combinations with the Greatest Burden on Public Health. University of Florida, Emerging Pathogens Institute, Gainesville, FL.

11. Berger, C. N., Brown, D. J., Shaw, R. K., Minuzzi, F., Feys, B., and Frankel, G. 2011. Salmonella enterica strains belonging to O serogroup 1,3,19 induce chlorosis and wilting of Arabidopsis thaliana leaves. Environ. Microbiol. 13(5):1299-1308. doi:10.1111/j.1462-2920.2011.02429.x

12. Berger, C. N., Shaw, R. K., Brown, D. J., Mather, H., Clare, S., Dougan, G., Pallen, M. J., and Frankel, G. 2009. Interaction of Salmonella enterica with basil and other salad leaves. ISME J. 3(2):261-255. doi:10.1038/ ismej.2008.95

13. Bleasdale, B., Lott, P. J., Jagannathan, A., Stevens, M. P., Birtles, R. J., and Wigley, P. 2009. The Salmonella pathogenicity island 2-encoded type III secretion system is essential for the survival of Salmonella enterica serovar Typhimurium in free-living amoebae. Appl. Environ. Microbiol. 75(6): 1793-1795. doi:10.1128/AEM.02033-08

14. Brandl, M. T. 2006. Fitness of human enteric pathogens on plants and implications for food safety. Annu. Rev. Phytopathol. 44:367-392. doi: 10.1146/annurev.phyto.44.070505.143359

15. Brandl, M. T. 2008. Plant lesions promote the rapid multiplication of Escherichia coli $\mathrm{O} 157: \mathrm{H7}$ on postharvest lettuce. Appl. Environ. Microbiol. 74(17):5285-5289. doi:10.1128/AEM.01073-08

16. Brandl, M. T., and Amundson, R. 2008. Leaf age as a risk factor in contamination of lettuce with Escherichia coli 0157:H7 and Salmonella enterica. Appl. Environ. Microbiol. 74(8):2298-2306. doi:10.1128/ AEM.02459-07

17. Brandl, M. T., Carter, M. Q., Parker, C. T., Chapman, M. R., Huynh, S., and Zhou, Y. 2011. Salmonella biofilm formation on Aspergillus niger involves cellulose-chitin interactions. PLoS One 6(10):e25553. doi:10.1371/ journal.pone. 0025553

18. Brandl, M. T., and Mandrell, R. E. 2002. Fitness of Salmonella enterica serovar Thompson in the cilantro phyllosphere. Appl. Environ. Microbiol. 68(7):3614-3621.

19. Brandl, M. T., Miller, W. G., Bates, A. H., and Mandrell, R. E. 2005. Production of autoinducer 2 in Salmonella enterica serovar Thompson contributes to its fitness in chickens but not on cilantro leaf surfaces. Appl. Environ. Microbiol. 71(5):2653-2662. doi:10.1128/AEM.71.5.26532662.2005

20. Brandl, M. T., Rosenthal, B. M., Haxo, A. F., and Berk, S. G. 2005. Enhanced survival of Salmonella enterica in vesicles released by a soilborne Tetrahymena species. Appl. Environ. Microbiol. 71(3):15621569. doi:10.1128/AEM.71.3.1562-1569.2005

21. Carter, M. Q., Brandl, M. T., Louie, J. W., Kyle, J. L., Carychao, D. K., Cooley, M. B., Parker, C. T., Bates, A. H., and Mandrell, R. E. 2011. Distinct acid resistance and survival fitness displayed by curli variants of enterohemorrhagic Escherichia coli O157:H7. Appl. Environ. Microbiol. 77(11):3685-3695. doi:Doi 10.1128/Aem.02315-10

22. Carter, M. Q., Xue, K., Brandl, M. T., Liu, F., Wu, L., Louie, J. W., Mandrell, R. E., and Zhou, J. 2012. Functional metagenomics of Escherichia coli $\mathrm{O} 157: \mathrm{H} 7$ interactions with spinach indigenous microorganisms during biofilm formation. PLoS One 7(9):e44186. doi: 10.1371/journal.pone.0044186

23. Cooley, M. B., Chao, D., and Mandrell, R. E. 2006. Escherichia coli O157:H7 survival and growth on lettuce is altered by the presence of epiphytic bacteria. J. Food Prot. 69(10):2329-2335.

24. Cooley, M. B., Miller, W. G., and Mandrell, R. E. 2003. Colonization of Arabidopsis thaliana with Salmonella enterica and enterohemorrhagic Escherichia coli O157:H7 and competition by Enterobacter asburiae. Appl. Environ. Microbiol. 69(8):4915-4926.

25. Cox, C. E., McClelland, M., and Teplitski, M. 2013. Consequences of disrupting Salmonella AI-2 signaling on interactions within soft rots. Phytopathology 103:352-361.

26. deWaal, C. S., Tian, X. A., and Plunkett, D. 2009. Outbreak Alert! Center for Science in Public Interest. Center for Science in the Public Interest, Washington, DC. http://cspinet.org/new/pdf/outbreakalertreprot09.pdf

27. Dong, Y., Iniguez, A. L., Ahmer, B. M., and Triplett, E. W. 2003. Kinetics and strain specificity of rhizosphere and endophytic colonization by enteric bacteria on seedlings of Medicago sativa and Medicago truncatula. Appl. Environ. Microbiol. 69(3):1783-1790.

28. Dorsey, C. W., Laarakker, M. C., Humphries, A. D., Weening, E. H., and Baumler, A. J. 2005. Salmonella enterica serotype Typhimurium MisL is an intestinal colonization factor that binds fibronectin. Mol. Microbiol. 57(1):196-211. doi:10.1111/j.1365-2958.2005.04666.x

29. Ercolani, G. L. 1979. Differential survival of Salmonella Typhi, Escherichia coli, and Enterobacter aerogenes on lettuce in the field. Zentralbl. 
Bakteriol. Naturwiss. 134(5):402-411.

30. Fett, W. F. 2006. Inhibition of Salmonella enterica by plant-associated pseudomonads in vitro and on sprouting alfalfa seed. J. Food Prot. 69(4):719-728.

31. Foster, J. W., and Spector, M. P. 1995. How Salmonella survive against the odds. Annu. Rev. Microbiol. 49:145-174. doi:10.1146/annurev.mi. 49.100195.001045

32. Gal, M., Preston, G. M., Massey, R. C., Spiers, A. J., and Rainey, P. B. 2003. Genes encoding a cellulosic polymer contribute toward the ecological success of Pseudomonas fluorescens SBW25 on plant surfaces. Mol. Ecol. 12(11):3109-3121.

33. Gaze, W. H., Burroughs, N., Gallagher, M. P., and Wellington, E. M. 2003. Interactions between Salmonella typhimurium and Acanthamoeba polyphaga, and observation of a new mode of intracellular growth within contractile vacuoles. Microbiol. Ecol. 46(3):358-369. doi:10.1007/ s00248-003-1001-3

34. Goudeau, D. M., Parker, C. T., Zhou, Y., Sela, S., Kroupitski, Y., and Brandl, M. T. 2013. The Salmonella transcriptome in lettuce and cilantro soft rot reveals a niche overlap with the animal host intestine. Appl. Environ. Microbiol. 79:250-262. doi:10.1128/AEM.02290-12

35. Gourabathini, P., Brandl, M. T., Redding, K. S., Gunderson, J. H., and Berk, S. G. 2008. Interactions between food-borne pathogens and protozoa isolated from lettuce and spinach. Appl. Environ. Microbiol. 74(8):2518-2525. doi:10.1128/AEM.02709-07

36. Guo, X., Chen, J., Brackett, R. E., and Beuchat, L. R. 2001. Survival of salmonellae on and in tomato plants from the time of inoculation at flowering and early stages of fruit development through fruit ripening. Appl. Environ. Microbiol. 67(10):4760-4764.

37. Harvey, P. C., Watson, M., Hulme, S., Jones, M. A., Lovell, M., Berchieri, A., Jr., Young, J., Bumstead, N., and Barrow, P. 2011. Salmonella enterica serovar Typhimurium colonizing the lumen of the chicken intestine grows slowly and upregulates a unique set of virulence and metabolism genes. Infect. Immun. 79(10):4105-4121. doi:10.1128/IAI.01390-10

38. Hirano, S. S., and Upper, C. D. 2000. Bacteria in the leaf ecosystem with emphasis on Pseudomonas syringae-a pathogen, ice nucleus, and epiphyte. Microbiol. Mol. Biol. Rev. 64(3):624-653.

39. Iniguez, A. L., Dong, Y. M., Carter, H. D., Ahmer, B. M. M., Stone, J. M., and Triplett, E. W. 2005. Regulation of enteric endophytic bacterial colonization by plant defenses. Mol. Plant-Microbe Interact. 18:169-178. doi:10.1094/mpmi-18-0169

40. Islam, M., Morgan, J., Doyle, M. P., Phatak, S. C., Millner, P., and Jiang, X. 2004. Persistence of Salmonella enterica serovar Typhimurium on lettuce and parsley and in soils on which they were grown in fields treated with contaminated manure composts or irrigation water. Foodborne Pathog. Dis. 1(1):27-35. doi:10.1089/153531404772914437

41. Islam, M., Morgan, J., Doyle, M. P., Phatak, S. C., Millner, P., and Jiang, X. 2004. Fate of Salmonella enterica serovar Typhimurium on carrots and radishes grown in fields treated with contaminated manure composts or irrigation water. Appl. Environ. Microbiol. 70(4):2497-2502.

42. Jablasone, J., Warriner, K., and Griffiths, M. 2005. Interactions of Escherichia coli O157:H7, Salmonella typhimurium and Listeria monocytogenes plants cultivated in a gnotobiotic system. Int. J. Food Microbiol. 99(1):7-18. doi:10.1016/j.ijfoodmicro.2004.06.011

43. Janisiewicz, W. J., Conway, W. S., and Leverentz, B. 1999. Biological control of postharvest decays of apple can prevent growth of Escherichia coli O157: H7 in apple wounds. J. Food Prot. 62(12):1372-1375.

44. Klerks, M. M., Franz, E., van Gent-Pelzer, M., Zijlstra, C., and van Bruggen, A. H. 2007. Differential interaction of Salmonella enterica serovars with lettuce cultivars and plant-microbe factors influencing the colonization efficiency. ISME J. 1:620-631.

45. Klumpp, J., and Fuchs, T. M. 2007. Identification of novel genes in genomic islands that contribute to Salmonella Typhimurium replication in macrophages. Microbiology 153(Pt 4):1207-1220. doi:10.1099/mic. $0.2006 / 004747-0$

46. Kobayashi, D., and Hillman, B. I. 2005. Fungi, bacteria, and viruses as pathogens of the fungal community. In: The Fungal Community: Its Organization and Role in the Ecosystem. J. Dighton, J. F. White, and P. V. Oudemans, eds. CRC Press, Boca Raton, FL.

47. Kroupitski, Y., Brandl, M. T., Pinto, R., Belausov, E., Tamir-Ariel, D., Burdman, S., and Sela, S. 2013. Identification of Salmonella enterica genes with a role in persistence on lettuce leaves during cold-storage by recombinase-based in vivo expression technology. Phytopathology $103: 362-372$

48. Kroupitski, Y., Golberg, D., Belausov, E., Pinto, R., Swartzberg, D., Granot D., and Sela, S. 2009. Internalization of Salmonella enterica in leaves is induced by light and involves chemotaxis and penetration through open stomata. Appl. Environ. Microbiol. 75(19):6076-6086. doi:10.1128/Aem.01084-09

49. Kroupitski, Y., Pinto, R., Belausov, E., and Sela, S. 2011. Distribution of
Salmonella typhimurium in romaine lettuce leaves. Food Microbiol. 28(5):990-997. doi:10.1016/J.Fm.2011.01.007

50. Kroupitski, Y., Pinto, R., Brandl, M. T., Belausov, E., and Sela, S. 2009. Interactions of Salmonella enterica with lettuce leaves. J. Appl. Microbiol. 106(6):1876-1885. doi:10.1111/J.1365-2672.2009.04152.X

51. Kyle, J. L., Parker, C. T., Goudeau, D., and Brandl, M. T. 2010. Transcriptome analysis of Escherichia coli O157: H7 exposed to lysates of lettuce leaves. Appl. Environ. Microbiol. 76(5):1375-1387. doi: 10.1128/AEM.02461-09

52. Lapidot, A., and Yaron, S. 2009. Transfer of Salmonella enterica serovar Typhimurium from contaminated irrigation water to parsley is dependent on curli and cellulose, the biofilm matrix components. J. Food Prot. 72(3):618-23.

53. Ledeboer, N. A., Frye, J. G., McClelland, M., and Jones, B. D. 2006. Salmonella enterica serovar Typhimurium requires the Lpf, Pef, and Tafi fimbriae for biofilm formation on HEp-2 tissue culture cells and chicken intestinal epithelium. Infect. Immun. 74(6):3156-3169. doi:10.1128/ IAI.01428-05

54. Leveau, J. H., and Lindow, S. E. 2001. Appetite of an epiphyte: Quantitative monitoring of bacterial sugar consumption in the phyllosphere. Proc. Natl. Acad. Sci. USA 98(6):3446-3453. doi:10.1073/ pnas.061629598

55. Lindow, S. E., and Brandl, M. T. 2003. Microbiology of the phyllosphere. Appl. Environ. Microbiol. 69(4):1875-1883.

56. Lopez-Velasco, G., Tydings, H. A., Boyer, R. R., Falkinham, J. O., and Ponder, M. A. 2012. Characterization of interactions between Escherichia coli $\mathrm{O} 157: \mathrm{H} 7$ with epiphytic bacteria in vitro and on spinach leaf surfaces. Int. J. Food Microbiol. 153:351-357.

57. Lynch, M. F., Tauxe, R. V., and Hedberg, C. W. 2009. The growing burden of foodborn outbreaks due to contaminated fresh produce: Risks and opportunities. Epidemiol. Infect. 137:307-315.

58. Mandrell, R. 2009. Enteric human pathogens associated with fresh produce: Sources, transport, and ecology. In: Microbial Safety of Fresh Produce. X. Fan, B. A. Niemira, C. J. Doona, F. E. Feeherry, and R. B. Gravani, eds. Blackwell Publishing and the Institute of Food Technologies, Ames, IA.

59. Matthysse, A. G., Deora, R., Mishra, M., and Torres, A. G. 2008. Polysaccharides cellulose, poly-beta-1,6-n-acetyl-D-glucosamine, and colanic acid are required for optimal binding of Escherichia coli O157:H7 strains to alfalfa sprouts and K-12 strains to plastic but not for binding to epithelial cells. Appl. Environ. Microbiol. 74(8):2384-2390. doi:10.1128/ AEM.01854-07

60. Matthysse, A. G., and McMahan, S. 1998. Root colonization by Agrobacterium tumefaciens is reduced in $c e l$, attB, attD, and attR mutants. Appl. Environ. Microbiol. 64(7):2341-2345.

61. Noel, J. T., Arrach, N., Alagely, A., McClelland, M., and Teplitski, M. 2010. Specific responses of Salmonella enterica to tomato varieties and fruit ripeness identified by in vivo expression technology. PLoS One 5(8). doi:10.1371/journal.pone.0012406

62. Noel, J. T., Joy, J., Smith, J. N., Fatica, M., Schneider, K. R., Ahmer, B. M., and Teplitski, M. 2010. Salmonella SdiA recognizes N-acyl homoserine lactone signals from Pectobacterium carotovorum in vitro, but not in a bacterial soft rot. Mol. Plant-Microbe Interact. 23:273-282. doi:10.1094/MPMI-23-3-0273

63. Poza-Carrion, C., Suslow, T. V., and Lindow, S. E. 2013. Resident bacteria on leaves enhance survival of immigrant cells of Salmonella enterica. Phytopathology 103:341-351.

64. Quilliam, R. S., Williams, A. P., and Jones, D. L. 2012. Lettuce cultivar mediates both phyllosphere and rhizosphere activity of Escherichia coli O157:H7. Plos One 7(3).

65. Rastogi, G., Sbodio, A., Tech, J. J., Suslow, T. V., Coaker, G. L., and Leveau, J. H. 2012. Leaf microbiota in an agroecosystem: Spatiotemporal variation in bacterial community composition on field-grown lettuce. ISME J. doi:10.1038/ismej.2012.32

66. Rehfuss, M. Y., Parker, C. T., and Brandl, M. T. 2011. Salmonella transcriptional signature in Tetrahymena phagosomes and role of acid tolerance in passage through the protist. ISME J. 5(2):262-273. doi:10.1038/ismej.2010.128

67. Romling, U. 2005. Characterization of the rdar morphotype, a multicellular behaviour in Enterobacteriaceae. Cell. Mol. Life Sci. 62(11): 1234-1246. doi:10.1007/S00018-005-4557-X

68. Romling, U., Bokranz, W., Rabsch, W., Zogaj, X., Nimtz, M., and Tschape, H. 2003. Occurrence and regulation of the multicellular morphotype in Salmonella serovars important in human disease. Intl. J. Med. Microbiol. 293:273-285. doi:10.1078/1438-4221-00268

69. Roy, D., Panchal, S., Rosa, B. A., and Melotto, M. 2013. Escherichia coli O157:H7 induces stronger plant immunity than Salmonella enterica Typhimurium SL1344. Phytopathology 103:326-332.

70. Sabag-Daigle, A., and Ahmer, B. M. 2012. ExpI and PhzI are descendants 
of the long lost cognate signal synthase for SdiA. PLoS One 7(10): e47720. doi:10.1371/journal.pone.0047720

71. Samrakandi, M. M., Ridenour, D. A., Yan, L., and Cirillo, J. D. 2002. Entry into host cells by Legionella. Front Biosci. 7:1-11.

72. Schikora, A., Carreri, A., Charpentier, E., and Hirt, H. 2008. The dark side of the salad: Salmonella Ryphimurium overcomes the innate immune response of Arabidopsis thaliana and shows an endopathogenic lifestyle. PLoS One 3(5):e2279. doi:10.1371/journal.pone.0002279

73. Schikora, A., Virlogeux-Payant, I., Bueso, E., Garcia, A. V., Nilau, T., Charrier, A., Pelletier, S., Menanteau, P., Baccarini, M., Velge, P., and Hirt, H. 2011. Conservation of Salmonella infection mechanisms in plants and animals. PLoS One 6(9):e24112. doi:10.1371/journal.pone.0024112

74. Semenov, A. M., Kuprianov, A. A., and van Bruggen, A. H. 2010. Transfer of enteric pathogens to successive habitats as part of microbial cycles. Microbiol. Ecol. 60:239-249. doi:10.1007/s00248-010-9663-0

75. Shirron, N., and Yaron, S. 2011. Active suppression of early immune response in tobacco by the human pathogen Salmonella Typhimurium. PLoS One 6(4):e18855. doi:10.1371/journal.pone.0018855

76. Solomon, E. B., Niemira, B. A., Sapers, G. M., and Annous, B. A. 2005. Biofilrn formation, cellulose production, and curli biosynthesis by Salmonella originating from produce, animal, and clinical sources. J. Food Prot. 68:906-912.

77. Teplitski, M., Noel, J. T., Alagely, A., and Danyluk, M. D. 2012. Functional genomics studies shed light on the nutrition and gene expression of non-typhoidal Salmonella and enterovirulent $E$. coli in produce. Food Res. Int. 45:576-586. doi:10.1016/J.Foodres.2011.06.020

78. Teplitski, M., Warriner, K., Bartz, J., and Schneider, K. R. 2011. Untangling metabolic and communication networks: Interactions of enterics with phytobacteria and their implications in produce safety. Trends Microbiol. 19(3):121-127. doi:10.1016/J.Tim.2010.11.007

79. Tezcan-Merdol, D., Ljungstrom, M., Winiecka-Krusnell, J., Linder, E., Engstrand, L., and Rhen, M. 2004. Uptake and replication of Salmonella enterica in Acanthamoeba rhysodes. Appl. Environ. Microbiol. 70(6): 3706-3714. doi:10.1128/AEM.70.6.3706-3714.2004

80. Thiennimitr, P., Winter, S. E., and Baumler, A. J. 2012. Salmonella, the host and its microbiota. Curr. Opin. Microbiol. 15(1):108-114. doi: 10.1016/j.mib.2011.10.002

81. Thiennimitr, P., Winter, S. E., Winter, M. G., Xavier, M. N., Tolstikov, V., Huseby, D. L., Sterzenbach, T., Tsolis, R. M., Roth, J. R., and Baumler, A. J. 2011. Intestinal inflammation allows Salmonella to use ethanolamine to compete with the microbiota. Proc. Natl. Acad. Sci. USA 108(42):17480-17485. doi:10.1073/pnas. 1107857108

82. Thilmony, R., Underwood, W., and He, S. Y. 2006. Genome-wide tran- scriptional analysis of the Arabidopsis thaliana interaction with the plant pathogen Pseudomonas syringae pv. tomato DC3000 and the human pathogen Escherichia coli O157:H7. Plant J. 46:34-53. doi:10.1111/ j.1365-313X.2006.02725.x

83. Turnbull, A. L., and Surette, M. G. 2008. L-Cysteine is required for induced antibiotic resistance in actively swarming Salmonella enterica serovar Typhimurium. Microbiology 154(Pt 11):3410-3419. doi:10.1099/ mic.0.2008/020347-0

84. Turnbull, A. L., and Surette, M. G. 2010. Cysteine biosynthesis, oxidative stress and antibiotic resistance in Salmonella Typhimurium. Res. Microbiol. 161:643-650. doi:10.1016/j.resmic.2010.06.004

85. Ustun, S., Muller, P., Palmisano, R., Hensel, M., and Bornke, F. 2012. SseF, a type III effector protein from the mammalian pathogen Salmonella enterica, requires resistance-gene-mediated signalling to activate cell death in the model plant Nicotiana benthamiana. New Phytol. 194(4):1046-1060. doi:10.1111/j.1469-8137.2012.04124.x

86. Wade, W. N., and Beuchat, L. R. 2003. Metabiosis of proteolytic moulds and Salmonella in raw, ripe tomatoes. J. Appl. Microbiol. 95:437-450.

87. Wade, W. N., Vasdinnyei, R., Deak, T., and Beuchat, L. R. 2003. Proteolytic yeasts isolated from raw, ripe tomatoes and metabiotic association of Geotrichum candidum with Salmonella. Int. J. Food Microbiol. 86(1-2):101-111.

88. Wang, Q., Frye, J. G., McClelland, M., and Harshey, R. M. 2004. Gene expression patterns during swarming in Salmonella typhimurium: Genes specific to surface growth and putative new motility and pathogenicity genes. Mol. Microbiol. 52:169-187. doi:10.1111/j.1365-2958.2003.03977.x

89. Wells, J. M., and Butterfield, J. E. 1997. Salmonella contamination associated with bacterial soft rot of fresh fruits and vegetables in the marketplace. Plant Dis. 81:867-872.

90. Wells, J. M., and Butterfield, J. E. 1999. Incidence of Salmonella on fresh fruits and vegetables affected by fungal rots or physical injury. Plant Dis. 83:722-726.

91. Winter, S. E., and Baumler, A. J. 2011. A breathtaking feat: To compete with the gut microbiota, Salmonella drives its host to provide a respiratory electron acceptor. Gut Microbes 2:58-60. doi:10.4161/gmic.2.1.14911

92. Yamazaki, A., Li, J., Hutchins, W. C., Wang, L., Ma, J., Ibekwe, A. M., and Yang, C. H. 2011. Commensal effect of pectate lyases secreted from Dickeya dadantii on proliferation of Escherichia coli O157:H7 EDL933 on lettuce leaves. Appl. Environ. Microbiol. 77:156-162. doi:10.1128/ AEM.01079-10

93. Zaragoza, W. J., Noel, J. T., and Teplitski, M. 2012. Spontaneous non-rdar mutations increase fitness of Salmonella in plants. Environ. Microbiol. Rep. 4:453-458. 